\title{
Eye Conditions among Fire Officers in the Brong Ahafo Region, Ghana
}

\author{
David Ben Kumah ${ }^{1 *}$, Abdul - Kabir Mohammed ${ }^{1}$, Reynolds Kwame Ablordeppey ${ }^{1}$, Edmund \\ Arthur $^{1}$, Sylvester Kyeremeh ${ }^{1}$ and Eugene Appenteng Osae ${ }^{1}$ \\ ${ }^{1}$ Department of Optometry and Visual Science, Kwame Nkrumah University of Science and Technology, Kumasi, Ghana
}

Received: 11 November, 2016; Accepted: 26 December, 2016 ; Published: 04 January, 2017

*Corresponding author: David Ben Kumah, Department of Optometry and Visual Science, Kwame Nkrumah University of Science and Technology, Kumasi, Ghana; E- mail: ben56kay@gmail.com

\begin{abstract}
Some occupations pose significant health threats to those involved with them. We investigated the prevalence of eye diseases among the fire service personnel in the Brong Ahafo Region of Ghana. This cross sectional screening - based study involved 160 personnel (115 males and 45 females) with mean $( \pm$ SD) age of $38.50 \pm 9.96$ years across 4 fire stations in the region (80\% participatory rate). History taken from the participants included their demographics, occupational and ocular history. Eye examinations included visual acuity, anterior segment assessment and funduscopy. Data was analyzed using IBM SPSS Statistics (version 21.0); we employed descriptive statistics, Fisher's exact test and Pearson's correlation. $\mathrm{P}<$ 0.05 was considered significant. Overall prevalence of eye conditions was $59.4 \%$. Pterygium was the most prevalence condition $(20.0 \%)$ and corneal lesions were the least (5.0\%). Number of years spent in the work correlated weakly with the number cases of eye conditions $[r=-0.23, p=0.66]$. Difference in prevalence of eye diseases among gender groups was significant $(\mathrm{p}<0.05)$. There was an overall high prevalence of eye diseases. We recommend frequent eye examination for fire officers in the area.
\end{abstract}

Keywords: Morbidity; Eye diseases; Pterygium; Occupational hazards; Fire officers

\section{Introduction}

Ocular morbidity describes a symptom or disease state of the eye which may be clinically relevant that the affected individual ought to be concerned enough about the condition to seek care. It may also be an eye condition of clinical relevance to an eye health professional and as such may determine whether an individual would benefit from advice, further review or treatment [1]. Work-related hazards have been identified as causes of ocular morbidity among persons in different occupational settings [2-5].

There are a myriad of causes of occupation related ocular anomalies; these may include flying particles, fragments, electrical sparks, dust, chemicals like lead and mercury, organic solvents, ionizing and non- ionizing radiation [6]. Exposures to these toxic agents predispose the eyes to ocular surface pathologies in a continuum of eye irritations, pterygium, pinguecula, dry eye syndrome, conjunctivitis and anterior uveitis. Radiation and extreme thermal effects have been implicated in photo retinits, eyelid burns and opacification of the crystalline lens [7].

Fire officers are one of the groups of professionals who are frequently exposed to these occupational hazards [8]; in combating fire, firefighters could be exposed to higher temperatures ranging from $1200 \mathrm{oC}$ to $1400 \mathrm{oC}$ from thermal sources such as hot surfaces, blankets of smoke and hot vapors. These adversely affect their general health as well as their ocular health. They find themselves almost always in unsafe environments when fighting fires and in the absence of proper safety measures and adequate personal protective equipment [2] could suffer eye diseases and general ill health.

We herein, attempted to investigate the prevalence of eye diseases among fire service personnel in the Brong Ahafo Region of Ghana.

\section{Materials and Methods}

\section{Recruitment of Study Subjects}

The Ghana National Fire Service has a number of district centers in the Brong Ahafo region with a total population of 419 fire service personnel at the time of the study. Using a confidence level of $95 \%$, an expected frequency of $50 \%$ and a margin of error of $6.5 \%$, a minimum sample size of 200 was determined by using the StatCalc function on Epi Info®) software version 7 (Centre for Disease Control, Atlanta, Georgia, USA). We conducted a cross sectional study across 4 fire stations in the Brong Ahafo Region of Ghana. We conveniently sampled 200 fire officers, out of which 160 personnel (80\% participatory rate) turned up for screening for ophthalmic (eye) conditions.

\section{Data Collection Procedures}

Participants were issued with interviewer - administered questionnaires to provide information on their demographics, occupational history and eye health. Funduscopy was carried out using a Welch Allyn Direct Ophthalmoscope (Welch Allyn, Inc. New York, USA). Anterior eye examination was performed with ophthalmic magnifying loupes and a pentorch. Visual acuity was measured with a distant Snellen visual acuity chart at 6 meters 
with back luminance of $160 \mathrm{~cd} / \mathrm{m} 2$. Data was analyzed using the IBM SPSS Statistics (version 21.0, Armonk, NY, IBM Corp). Descriptive statistics, Pearson's Correlations and Chi-squared test of associations were performed. Continuous variables are expressed as mean \pm standard deviation $(\mathrm{M} \pm \mathrm{SD})$. For all analysis, $\mathrm{p}<0.05$ was considered significant.

\section{Ethical Consideration}

The study was conducted according to the tenets of the Declaration of Helsinki [9]. We sought for and obtained informed consent from all of the participants after explaining the study to them. Permission to carry out the study was also sought from the authorities at the four fire stations.

\section{Results}

There was an overall $80 \%$ participatory rate -160 participants (115 males and 45 females) responded to the questionnaire and presented for eye examination. Overall mean age was $38.50 \pm$ 9.96 years. Table 1 summarizes information on participants' demographics. There was statistically significant difference ( $p$ $<0.05$ ) in the distribution of males and females in the various departments of operation (Table 2).

We detected various eye diseases on screening the participants. These included pterygium, pinguecula, conjunctivitis and cataracts. Overall prevalence of eye diseases was $59.4 \%$. The most prevalent condition was pterygium $(20.0 \%)$ and the least were corneal lesions (corneal opacities/scars) forming 5.0\% of the cases. Figure 1 shows the prevalence of the various eye diseases.

The difference in the distribution of the different eye conditions was significantly higher among the males than females $(p<0.05)$. Figure 2 shows how the conditions were distributed among females and males.

Upon questioning, it was found that $69.9 \%$ of the workers in Operation/Rural Fires had frequent exposure to hazards with about $68.5 \%$ of them having average exposure time of five hours.

The number cases of the different conditions correlated weakly with length of working experiences $[r=-0.23, p=0.66]$, (figure 3).

Generally, the prevalence of ocular morbidity increased with non-use of use of ocular protection devices ( $p<0.05)$. In agreement to this, results from this work shows that workers who did not have any eye protection suffered higher prevalence

\begin{tabular}{|c|c|c|c|}
\hline Table 1: Age and gender distribution of participants \\
\hline \multirow{2}{*}{$\begin{array}{c}\text { Age Group } \\
\text { (years) }\end{array}$} & \multicolumn{2}{|c|}{ Gender } & \multirow{2}{*}{ Total } \\
\cline { 2 - 3 } & Male & Female & \\
\hline $21-30$ & 26 & 16 & 42 \\
\hline $41-40$ & 34 & 14 & 48 \\
\hline $51-50$ & 37 & 13 & 50 \\
\hline Total & 18 & 2 & 20 \\
\hline
\end{tabular}

Table 2: Percentage distribution of male and female fire officers in the various departments of operation

\begin{tabular}{|c|c|c|c|}
\hline Gender & $\begin{array}{c}\text { Operational Fires } \\
(\mathbf{n = 7 4 )}\end{array}$ & $\begin{array}{c}\text { Administration } \\
(\mathbf{n = 1 6 )}\end{array}$ & $\begin{array}{c}* \text { Others ( } \mathbf{n}= \\
\mathbf{7 0})\end{array}$ \\
\hline Males & $100 \%$ & $25 \%$ & $58.60 \%$ \\
\hline Females & $0 \%$ & $75 \%$ & $41.40 \%$ \\
\hline
\end{tabular}

*0thers include the following departments: 1 Safety and Education 2 Emergency Medical Tech/Ambulance3 Training 4 Transport $\mathbf{5}$ Housekeeping 6 Project and Instruction

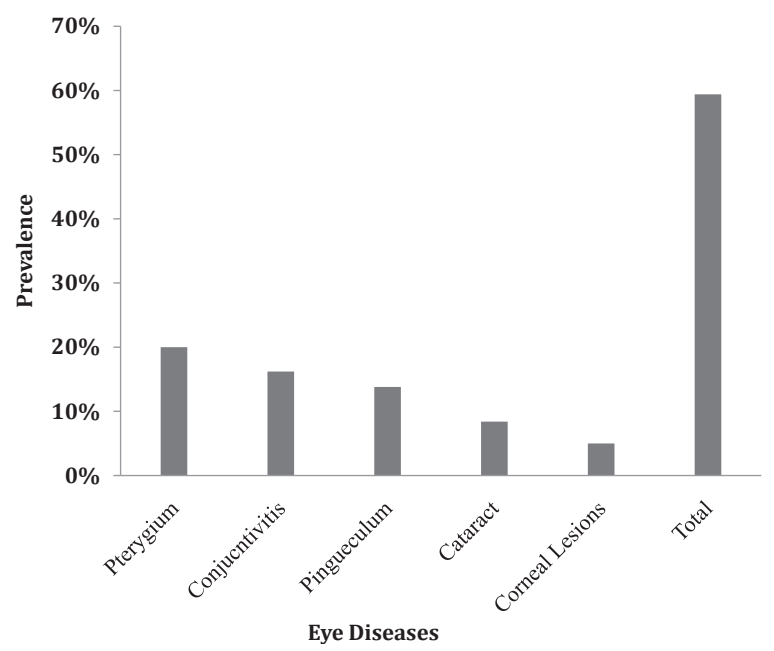

Figure 1: Prevalence of the various eye diseases detected

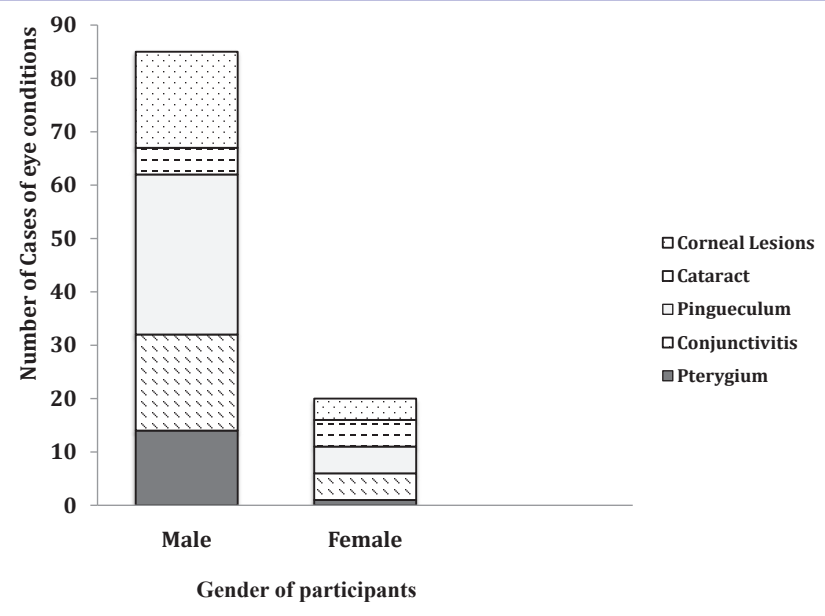

Figure 2: Distribution of the detected eye conditions among male and female fire officers

For all the cases of the various eye conditions observed, the distribution was significantly higher $(\mathrm{p}<0.05)$ among officers in the operational fires department. Table 3 shows this observation.

of conjunctivitis compared with those who had some form of eye protection devices $(p<0.05)$. Seventy-five percent of the pterygium cases and $86.37 \%$ of all pinguecula cases were found among the workers who had no eye protection. This trend is seen in all other ocular conditions recorded as shown in Table 4. 


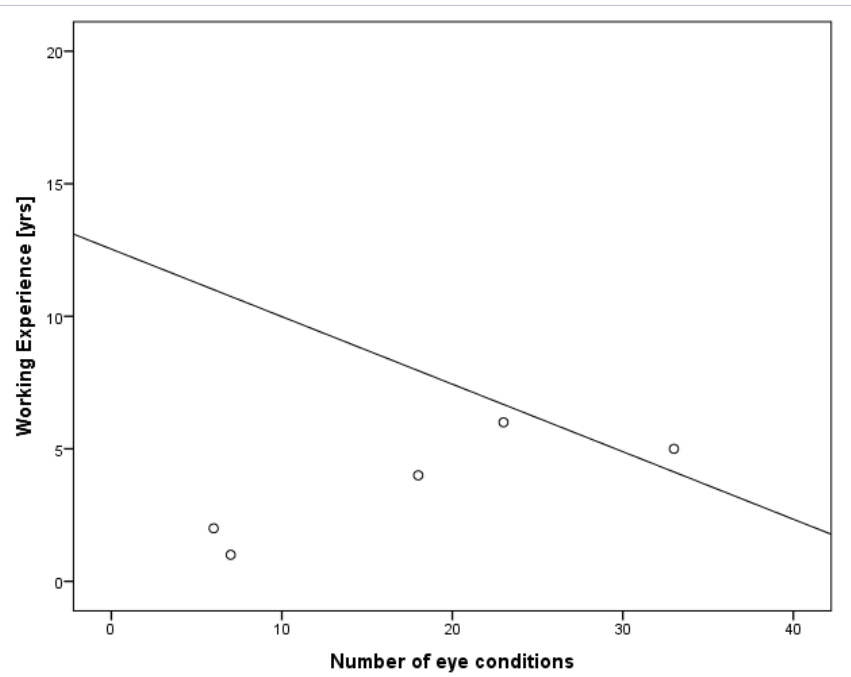

Figure 3: Relation between working experience and number of eye conditions

Table 3: Distribution of eye diseases among various departments of Fire service operation

\begin{tabular}{|c|c|c|c|}
\hline Eye Condition & $\begin{array}{c}\text { Operational } \\
\text { Fires (n) }\end{array}$ & $\begin{array}{c}\text { Administration } \\
\text { (n) }\end{array}$ & Others (n) \\
\hline Pterygium & 24 & 2 & 6 \\
\hline Conjunctivitis & 18 & 1 & 7 \\
\hline Pinguecula & 14 & 3 & 5 \\
\hline Cataract & 7 & 0 & 0 \\
\hline Corneal Lesions & 5 & 1 & 2 \\
\hline
\end{tabular}

Table 4: Relation between Presence or Absence of Eye Protection and Ocular condition

\begin{tabular}{|c|c|c|c|}
\hline \multirow{2}{*}{ Condition } & \multicolumn{2}{|c|}{ Eye protection } & \multirow{2}{*}{ Total } \\
\cline { 2 - 3 } & Yes & No & \\
\hline Conjunctivitis & 8 & 18 & 26 \\
\hline Pterygium & 8 & 24 & 32 \\
\hline Pinguecula & 3 & 19 & 22 \\
\hline Corneal opacity & 1 & 4 & 5 \\
\hline Corneal arcus & 0 & 3 & 3 \\
\hline Cataract & 2 & 5 & 7 \\
\hline Total & 22 & 73 & 95 \\
\hline
\end{tabular}

\section{Discussion}

This study investigated the prevalence of eye diseases among fire service personnel in the Brong Ahafo Region of Ghana and thus provides important information on the state of their ocular health. The demographic reports showed a greater proportion of the fire service personnel being men. Most of the male respondents were involved in mainstream firefighting while activities of the females were mainly confined to administrative works. This uneven distribution may be due to the fire service profession being high risk as such is more attractive to men who are more likely to be involved in high risk occupations $[10,11]$.
The overall prevalence of ocular morbidity (59.38\%) reported in this study was lower than that reported in other high risk professions in Ghana [12, 13] and elsewhere [14] but slightly higher compared to that reported by Kumah et al.[15]. A plausible explanation for this could be the differences in sample size, age and sex of participants, and the difference in type of hazard and exposure time. There is an apparent similarity between our results and that of Fatouhiet et al. [16] whose study showed a higher prevalence $(\mathrm{p}<0.05)$ of ocular morbidity among male respondents in the Tehran eye study.

The high prevalence of conjunctival lesions is comparable to that found in other occupational based studies [12, 13, 15-17]. Some literature $[18,19]$ implicate the development of pterygium and pinguecula on hazardous environmental agents like heat, dust, oxides of chemicals, which are comparable to the harmful agents encountered by most of personnel of the fire service.

Alves et al. [20] points out that male subjects are at higher risk of developing conjunctival lesions. Even though these results do agree, our finding that eye conditions were more prevalent among male fire service personnel could be attributable to the higher number of male respondents as compared to females. Again, this finding could also be confounded by nature of occupational duties discharged by the respondents. Male fire officers are usually engaged in active fire combats while females discharge administrative duties. This means that the differences in work environments, duration of exposure to hazardous agents and individual physiological difference could all be confounders to this finding.

As was expected, results from direct questioning revealed that most of the personnel working in operation and rural fires department had longer exposure time to extreme heat, particulate matter, chemical oxides, smoke and noxious agents; this could account for the of distribution pattern of eye conditions among them. These toxic agents affect not only their ocular health but general health [21-23].

Alteration in the temperature gradient of ocular tissues such as corneal tissues leading to corneal lesions has been implicated in exposure to several forms of radiation [24, 25]. This study revealed corneal opacities and corneal arcus which aside the likelihood of systemic co-morbidities could have been excited by thermal radiation. Ageing and unhealthy lipid profiles could also modify the incidence of corneal arcus [18, 2426]. The development of cataract as found among some of the respondents have been established by some research to associate with radiation, age, sex and trauma from flying objects which fire service workers usually encounter in their work [18, 27-30]. The findings of the study showed cataract was commoner among males and among the aged groups (51-60 years) of fire service personnel.

The use of personal protective equipment including protective eyewear has been stated in some studies as costeffective intervention for preventing ocular morbidity (notably eye injuries). The use of eye protection is believed to save industries several millions of dollars [31, 32]. Our study revealed 
that, for all the eye conditions detected, personnel in the group that did not use any eye protection recorded higher counts. It will suffice to state that, the poorer their eye protection the greater the likelihood of developing an eye condition from a prolonged exposure to hazardous agents.

The prevalence of pterygium was higher in those who used no form eye protection $(p<0.05)$. Researchers have established that there is a higher percentage of risk among persons who never wear eye protection or brimmed hats in the sun [33]. This finding is comparable to some aspects of our study; information gathered from some of our respondents revealed that they sometimes work under sunny outdoor conditions during firefighting. As a result, those not using eye protection were prone to developing eye conditions. On the reverse, the prevalence of pinguecula in the group that did not use eye protection was not statistically insignificant $(p>0.05)$ even though there was an apparent higher prevalence $(n=19)$ than those who used eye protection $(n=3)$. The distribution of conjunctivitis also agrees with other studies $[13,14]$; conjunctivitis was more prevalent among those who did not use eye protection. Some personnel did not use eye protection for reasons of unavailability. Others did not wear because of reasons of lack of comfort or fit, scratching of eye and fogging. This agrees with the report of Lombardi et al. [34] but contrary to their reports our study respondents reported that they received periodic sufficient safety education and training.

Results from this study indicated no statistically significant difference between number of different ocular conditions and length of work experience of personnel. A longer working experience implies longer exposure to hazards, thus leading to development of certain ocular conditions. The unexpected results could be attributed to most of personnel being in certain departments that do not directly come into contact with these hazards, and relatively short working experience in members of the Operation/Rural Fires department.

This study is not without its limitations. Aside the potential for bias towards males in the results, slit lamp bio microscope and diagnostic agents such as fluorescein were not used, and as such certain conditions like incipient corneal ulcerations, incipient cataracts and dry eyes could have been missed.

\section{Conclusion}

The results of this research show that the most prevalent ocular conditions in the Ghana National Fire Service, Brong Ahafo region are (from most to least prevalent): pterygium, conjunctivitis, pinguecula, cataract, corneal opacity, and cornea lesions. The study has also shown there is a high prevalence among workers who did not use eye protection during their operations.

The high prevalence recorded in this study calls for pragmatic measures as periodic eye examinations, encouraging regular use of protective eyewear and health education programs to be instituted in a bid to ameliorate the current situation, prevent secondary complications and to reduce the burden of ocular conditions.

\section{Conflicts of Interest}

The authors declare that they have no conflict of interests regarding the publication of this manuscript.

\section{References}

1. Kimani K, Lindfield R, Senyonjo L, Mwaniki A, Schmidt E. Prevalence and causes of ocular morbidity in Mbeere District, Kenya. Results of a population-based survey. PloS one. 2013;8(8):e70009. doi: 10.1371/ journal.pone.0070009.

2. Griffith G, Jones N. Eye injury and eye protection: a survey of the chemical industry. Occupational medicine. 1994;44(1):37-40.

3. Lipscomb HJ. Effectiveness of interventions to prevent work-related eye injuries. American journal of preventive medicine. 2000;18(4 Suppl):27-32.

4. Schoemaker MJ, Barreto SM, Swerdlow AJ, Higgins CD, Carpenter RG. Non-fatal work related injuries in a cohort of Brazilian steelworkers. Occupational and environmental medicine. 2000;57(8):555-62.

5. Okoye O, Umeh R. Eye health of industrial workers in Southeastern Nigeria. West African journal of medicine. 2002;21(2):132-7.

6. Executive HaS. A Recipe for Safety: OccupationalHealth and Safety in Food and Drink Manufacture. 2005.

7. Khurana A. Diseases of the Lens. Comprehensive Ophthalmology 4th edition New Delhi: New Age International (p) Limited. 2007:170.

8. Patel HC, Rao NM, Saha A. Heat exposure effects among fire fighters. Indian Journal of Occupational and Environmental Medicine. 2006;10(3):121. doi: 10.4103/0019-5278.29572.

9. World Medical Association. World Medical Association Declaration of Helsinki. Ethical Principles for Medical Research Involving Human Subjects. Bull World Health Org. 2001;79(4):373-4.

10. Byrnes JP, Miller DC, Schafer WD. Gender differences in risk taking: a meta-analysis. Psychological Bulletin. 1999;125(3):367-83. doi: 10.1037/0033-2909.125.3.367.

11. Harris CR, Jenkins M, Glaser D. Gender Differences in Risk Assessment: Why do Women Take Fewer Risks than Men? Judgment and Decision Making. 2006;1(1):48-63.

12. Kumah DB, Bisiw JD, Abdul-Kabir M, Osae EA. Ocular conditions among singed-hide butchers at the Kumasi abattoir. Journal of Epidemiological Research. 2016;2(1):20-3.

13. Ovenseri-Ogbomo G, Ocansey S, Abu EK, Kyei S, Boadi-Kusi SB. OculoVisual Findings among Industrial MineWorkers at Goldfields Ghana Limited, Tarkwa. Ophthalmol Eye Dis. 2012;4:35-42. doi: 10.4137/ OED.S9204.

14. Titiyal JS, Murthy GV. Industrial ocular morbidity in a north Indian town. Indian J Public Health. 1998;42(2):29-33.

15. Kumah DB, Aikins S, Ansah AO, Akuffo KO, Osae EA. Eye Diseases among Women Engaged in Local Extraction of Palm Kernel Oil in the Kumasi Metropolis. Epidemiology Research International. 2014;2014.

16. Fotouhi A, Hashemi H, Khabazkhoob M, Mohammad K. Prevalence and risk factors of pterygium and pinguecula: The Tehran Eye Study. Eye (Lond). 2009;23(5):1125-9. doi: 10.1038/eye.2008.200.

17. Nakaishi H, Yamamoto M, Ishida M, Someya I, Yamada Y. Pingueculae and pterygia in motorcycle policemen. Ind Health. 1997;35(3):325-9.

18. Khurana AK. Comprehensive Ophthalmology. Fourth ed. New Delhi: New Age International Limited Publishers; 2007. 
19. Patel HC, Rao NM, Saha A. Heat exposure effects among firefighters. Indian J Occup Environ Med. 2006;10(3):121-3.

20. Alves LF, Fernandes BF, Burnier JV, Zoroquiain P, Eskenazi DT, Burnier Jr MN. Incidence of epithelial lesions of the conjunctiva in a review of 12,102 specimens in Canada (Quebec). Arquivos Brasileiros de Oftalmologia. 2011;74:21-3.

21. da Silva LF, Saldiva SR, Saldiva PH, Dolhnikoff M. Impaired lung function in individuals chronically exposed to biomass combustion. Environ Res. 2012;112:111-7. doi: 10.1016/j.envres.2011.10.012.

22. Hnizdo E, Esterhuizen TM, Rees D, Lalloo UG. Occupational asthma as identified by the Surveillance of Work-related and Occupational Respiratory Diseases programme in South Africa. Clinical \& Experimental Allergy. 2001;31(1):32-9.

23. Sukhsohale ND, Narlawar UW, Phatak MS. Indoor air pollution from biomass combustion and its adverse health effects in central India: an exposure-response study. Indian J Community Med. 2013;38(3):1627. doi:10.4103/0970-0218.116353.

24. Gaynor PM, Zhang WY, Salehizadeh B, Pettiford B, Kruth HS. Cholesterol accumulation in human cornea: evidence that extracellular cholesteryl ester-rich lipid particles deposit independently of foam cells. J Lipid Res. 1996;37(9):1849-61.

25.Zech LAJ, Hoeg MJ. Correlating corneal arcus with atherosclerosis in familial hypercholesterolemia. Lipids Health Dis. 2008;7:7. doi: 10.1186/1476-511X-7-7.

26. Crick RP, Khaw PT. A Textbook of Clinical Ophthalmology: A practical guide to disorders of eyes and their management. Third ed. Singapore: World Scientific; 2003.
27. Ainsbury EA, Bouffler S, Dörr W, Graw J, Muirhead CR, Edwaeds AA, et al. Radiation cataractogenesis: a review of recent studies. Radiat Res. 2009;172(1):1-9. doi: 10.1667/RR1688.1.

28. Riffle J. Floating anterior lens capsule: an unusual case of true exfoliation. Digit J Ophthalmol. 2010;16(4):17-9. doi: 10.5693/ djo.02.2010.10.001.

29. Voke J. Radiation effects on the eye, Part 1: Infrared radiation effects on ocular tissue. Optom Today. 1999;9:22-8.

30. Voke J. Radiation effects on the eye, Part 3b: Ocular effects of ultraviolet radiation. Optom Today. 1999;9:37-40.

31. Islam SS, Doyle EJ, Velilla A, Martin CJ, Ducatman AM. Epidemiology of compensable work-related ocular injuries and illnesses: incidence and risk factors. Journal of occupational and environmental medicine / American College of Occupational and Environmental Medicine. 2000 Jun;42(6):575-81.

32. Lombardi DA, Pannala R, Sorock GS, Wellman H, Courtney TK, Verma $\mathrm{S}$, et al. Welding related occupational eye injuries: a narrative analysis. Injury prevention : journal of the International Society for Child and Adolescent Injury Prevention. 2005 Jun;11(3):174-9.

33. McCarty CA, Fu CL, Taylor HR. Epidemiology of pterygium in Victoria, Australia. British Journal of Ophthalmology. 2000 March 1, 2000;84(3):289-92.

34. Lombardi DA, Verma SK, Brennan MJ, Perry MJ. Factors influencing worker use of personal protective eyewear. Accident; analysis and prevention. 2009 Jul;41(4):755-62. doi: 10.1016/j.aap.2009.03.017. 